\title{
Development and Performance Evaluation of a Liquid Soap Production Machine for
}

\section{Local Soap Industry in Nigeria}

\author{
OGEDENGBE, TI \\ Department of Mechanical Engineering, Federal University of Technology, Akure, Nigeria. \\ *Corresponding Email: tioged@yahoo.com; tiogedengbe@futa.edu.ng
}

\begin{abstract}
A liquid Soap production Machine was developed and evaluated to facilitate local production of liquid soap in Nigeria. A Preliminary study of the liquid soap production process was carried out within the local soap industry to collect necessary information and establish the appropriate production procedure. This was translated into the design concept of the machine. Detailed design of the components of the machine was done followed by its fabrication. The developed machine which was powered by a $1 \mathrm{Hp}(0.746 \mathrm{~kW})$ variable speed electric motor comprises a main mixer, two pre mixers, machine frame, V-belt drive and geared drive systems. All materials used in the fabrication of the machine were sourced locally. Result of machine evaluation revealed that the machine run smoothly in operation. Also, it was established that drudgery and fatigue associated with local production of liquid soap had been substantially reduced according to the responses from the users of the developed machine. The viscosity and turbidity of the liquid soap produced using the developed machine was found to be higher than that of the manually produced one while its viscosity was found satisfactorily at par with that of the liquid soap produced using one of the commercially available mixing machines (MMs). However, the cost of production of the machine developed herein and its subsequent maintenance cost is cheaper than that of the MMs.
\end{abstract}

\section{DOI: https://dx.doi.org/10.4314/jasem.v23i6.19}

Copyright: Copyright (C) 2019 Ogedengbe. This is an open access article distributed under the Creative Commons Attribution License (CCL), which permits unrestricted use, distribution, and reproduction in any medium, provided the original work is properly cited.

Dates: Received: 27 April 2019; Revised: 22 May 2019; Accepted 11 June 2019

Keywords: Design, development, evaluation, liquid soap production, mixing machine

The need for soap, a cleaning agent, is of high priority provided man understands the necessity to continually keep its environment clean. Soap was invented not only for the purpose of personal hygiene but also to solve other purposes (Warra, 2013). It has numerous applications in our daily life one of which is to keep our household and workplace better place to live and work. Hence, it is an essential commodity in the modern civilized world. Soap is a combination of fatty acids and alkalis obtained by reacting various animal and vegetable fats and oils with caustic soda or potash. It is produced by a saponification or basic hydrolysis reaction of fat or oil. Currently, sodium carbonate or sodium hydroxide is used to neutralize the fatty acid and convert it to salt (Charles, 2003). The final product is achieved through a series of steps with value addition at each step to fulfill and satisfy the expectations of the manufacturer and/or end users (Bashir, 2014). Soap can exist in three forms namely bar, powder and liquid. Liquid soap is the cleaning agent made available in liquid form. Until recently its production remained a primitive art due to the traditional means of mixing and/or stirring the chemical ingredients together, a process which is the same whether the production is done in a backyard or in a factory using manual approach or a dedicated machine. The simplicity of the process, particularly the fact that it can be achieved manually, has led to its general acceptance and practice as a small business operation. Mixing is used to produce a more uniform mixture of the soap ingredients. In the local soap industry, production is carried out through manual mixing. This conventional manual approach to liquid soap production demands hours of stirring by hand, hence it involves strenuous human efforts as it requires a lot of energy. Also, it requires a lot of time input by the soap producer. The manual mixing of the soap ingredients is usually accomplished with a stick or wooden ladle. The final product is usually not uniformly mixed due to fatigue usually suffered by the operator (Ajao et al., 2010). Therefore, in order to meet the increasing high demand for liquid soap around the world the process of production should be made easy. Consequently, Liquid Soap Mixing Machines (MMs) have been developed and are commercially available (Anon 2018). However, the commercially available MMs are not easily accessible to local manufacturers and/or small-scale enterprises (SSEs) as well as households to help them play their part in the production of liquid soap and in meeting users need. This is because the SSEs and, in particular, households cannot readily afford the MMs. Hence, the use of crude local equipment like buckets and wooden ladle stirrer, with the activities involved done 
manually is current being employed in the production of liquid soap by the SSEs and households in the Nigeria local soap industry. This approach is cheap to set up but it is very laborious, time consuming and usually results in lower productivity. Hence, it discourages prospective SSEs and households from venturing into the business of liquid soap production. Kililiku et al. (2006) designed and developed a mixing machine for making bar soap after carrying out survey on existing mechanized systems. The machine which is power by a $2 \mathrm{HP}, 240$ volts, $50 \mathrm{~Hz}$ electric motor consist basically of two main parts namely a) the mixer; and b) the soap plodder. The components of the machine were made from local materials to enable production of a cost effective bar soap making machine for the local soap industry in Nairobi, Kenya. The machine was designed and developed to operate at a speed of $60 \mathrm{rpm}$ hence a variable speed drive is used to reduce the very high speed of the electric motor to the operational speed of the machine. The machine was found to be economically viable after due analysis. However, the machine functionality is limited to the production of bar soap. Ajao et al. (2010) designed and developed a pedal powered liquid soap mixing machine with a capacity of 200 liters/batch of production. It consists of a chain drive and gear amplification mechanisms that turns impeller blades in a large stainless-steel container, where soap ingredients are stirred and blended. The study reported that the machine can be used by unskilled workers and save time when compared to traditional way of mixing liquid soap constituents. The machine was also reported to be economically viable. Much later, mold, cutting and stamping machines were developed, fabricated and tested alongside the pedal powered soap mixer for bar soap production (Ajao et al., 2011). However, even though the pedal powered liquid soap mixing machine is well adapted in rural areas where there is no electricity, it still involves a laborious process of pedaling. Also, it does not make provision for pre mixing of soap ingredients before charging them into the main mixture. This would still have to be accomplished by mixing manually before the premixed ingredients are added into the final mixture using this machine. Since the persistent problem with the efficiency of manual liquid soap production is the use of crude tools and expanded human effort that result in fatigue, the objective of this study, therefore, is to develop a liquid soap production machine that would reduce the fatigue involve and eliminate the use of crude tools which are still in existent in Ajao et al. (2010) design. Moreover, the target of this study is SSEs and/or households, hence it was decided to develop a prototype machine capable of producing 20 liters/batch of liquid soap.

\section{MATERIALS AND METHOD}

This study progressed through an exhaustive literature review, collection of relevant information through interview sessions, conceptual design, detailed design, fabrication of the machine and finally performance evaluation. Interview sessions were conducted with local liquid soap producers within some selected communities in Akure environ to get adequate understanding of the production process. The chemical ingredients required for the production of 20 litres of liquid soap were established to include (1) 125 $\mathrm{g}$ of Nitrosol; (2) $62.5 \mathrm{~g}$ of Caustic Soda; (3) $125 \mathrm{~g}$ of Soda Ash; (4) 1.5 liters of Sulphuric Acid; (5) $125 \mathrm{~g}$ of Texapon; (6) $62.5 \mathrm{~g}$ of Sodium Tripolyphosphate (STPP); (7) $125 \mathrm{~g}$ of Sodium Lauryl Sulphate (SLS); (8) $60 \mathrm{ml}$ of Perfume; and (9) Colour. The colour is usually provided in moderate quantity. Due to the peculiarity of the production process there are some of the ingredients that has to be mixed together or mixed with water before being poured into the main mixture that would form the liquid soap. Hence, the procedural sequence for production of the liquid soap which in turn facilitates the conceptualization of the design of the prototype liquid soap machine developed in this study was established, for the 20 liters capacity targeted in this study, as follows:

Addition of 15 liters of water into a main reservoir (1) Pour the Nitrosol into the 15 liters of water (1) and stir

Then, using a separate reservoir,

(2) Pour the Texapon and use the Sulphuric acid $\left(\mathrm{H}_{2} \mathrm{SO}_{4}\right)$ to mix. Stir appropriately. Thereafter, pour the mixture into (1) and stir

(3) Mix the Caustic soda with 1 liter of water and stir. Then pour mixture into (1) and stir

(4) Do Soda ash as in 4

(5) Do Sodium Lauryl Sulphate (SLS) as in 4

(6) Do Sodium Tripolyphosphate (STPP) as in 4

(7) Mix the perfume with 0.5 liter of water and stir. Then pour mixture into (1) and stir

(8) Do Colour as in 8

Thereafter continuous stirring of the whole mixture in the main reservoir is carried out until all lumps have disappear after which the product is packaged for use. An exhaustive consideration of this production procedural sequence facilitated the generation of different sketches and unscaled designs whose features and functionality were carefully examined to obtain a conceptual design. It was observed that many of the liquid soap ingredients require certain volume of water to be mixed with the solute before eventual discharge into the main reservoir where the final liquid soap mixture is being stirred for the final stage of production. This necessitates pre mixing operation and 
the incorporation of pre mixing chambers. Also, the design for the lid of the reservoir is done in such a way that it would be bolted down so it can be easily disassembled for maintenance purposes. Subsequently, with the use of a CAD software (SOLIDWORKS) the design features were translated and used in developing the conceptual design. The design features of the concept adopted are hinged on the following considerations: quality machine; cost effective machine; easy maintenance; safety of the operator; use of locally available materials and high functionality. The diagram of the conceptual design developed for the liquid soap production machine in this study is shown in Fig. 1. The machine was designed to use two pre mixers numbered 8 and one main mixer numbered 2 . The main mixer stirrer numbered 13 is driven by an electric motor through an open belt drive system. The main mixer stirrer shaft was designed to drive the two pre mixers stirrers through a gear train arrangement.

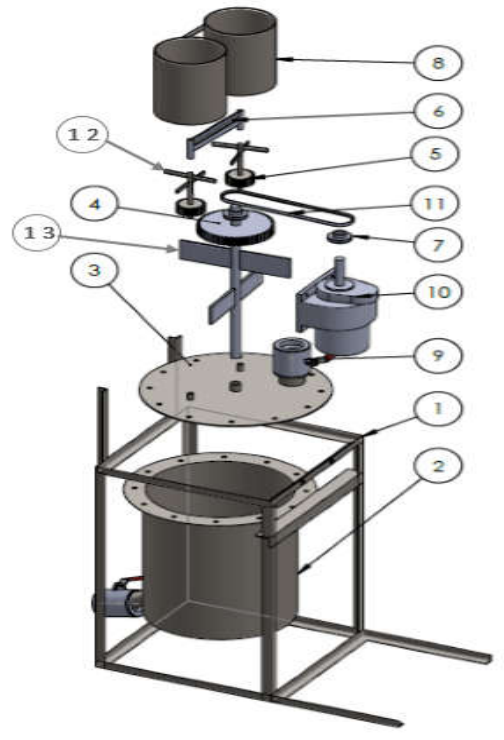

\begin{tabular}{|c|c|c|}
\hline $\begin{array}{c}\text { ITEM } \\
\text { NO. }\end{array}$ & PART NAME & QTY. \\
\hline 1 & Machine Frame & 1 \\
\hline 2 & Main Mring Chamber & 1 \\
\hline 3 & Cover & 1 \\
\hline 4 & A 75 Tooth Gear & 1 \\
\hline 5 & A 25 tooth Gear & 2 \\
\hline 6 & Pre Mixer Seat & 1 \\
\hline 7 & Pulley & 2 \\
\hline 8 & Pre Mixers & 2 \\
\hline 9 & Ball Valves & 2 \\
\hline 10 & Electric Motor & 1 \\
\hline 11 & v-Belt & 1 \\
\hline 12 & Pre Mixers Stirrer Blades & 4 \\
\hline 13 & Main Mixers Stirer Blades & 4 \\
\hline
\end{tabular}

Fig. 1. Exploded view of the Conceptual Design showing Components of the machine

The detailed design involves the determination of the design parameters of various components of the machine to be produced as well as the determination of the specification of the components to be bought off-the-shelf and assembled to achieve the machine. The detailed design was premised on the production capacity of 20 liters as a prototype.

Main mixer design: The Main mixer consists of the main mixing chamber, the Main mixer stirrer impeller and the Main mixer shaft. The design parameters of the main mixing chamber which is designed as a cylinder were obtained, using equation (1), after due consideration of the targeted output capacity of the machine being developed.

$V=\pi r^{2} h$

The height of the cylinder is appropriated to be equal to 1.25 of its diameter (for stability purpose). Therefore, the diameter, $\mathrm{D}$, of the cylindrical chamber is obtained to be $0.294 \mathrm{~m}$ and the height is $0.368 \mathrm{~m}$ for a volume of $0.025 \mathrm{~m}^{3}$ to provide adequate clearance for the product to be mixed. Four wall baffles, each having a width of $0.03 \mathrm{~m}$, which consist of flat vertical plates, directed radially, and spaced at $90^{\circ}$ intervals around the tank circumference is provided. The width, $\mathrm{W}$, of each baffle is calculated in respect of the diameter, $\mathrm{D}$, of the main mixing chamber according to Parvizi et al. (2016) and Jirout and Rieger (2011) as in Equation (2).

$W=0.1 D$

To mix the constituents of the liquid soap properly stirrer blades assemblies/impellers fixed on a stirrer shaft are required. In a high viscosity application, a close-clearance axial impeller is more practical for achieving uniform blend (Dickey and Fasano, 2004). Hence, two axial impellers each having three blades were employed in this design. The impellers are scaled to give workable clearance with respect to the dimensions of the main mixing chamber as given in Parvizi et al. (2016). This resulted in an impeller diameter of $0.147 \mathrm{~m}$. The Main mixer stirrer shaft being rotated by the electric motor is subjected to the torque $\mathrm{T}$ transmitted to it from the motor. Also, the shaft is loaded by the weight of the gear, the pulley and 
the impellers located on it as well as the force due to the stirring action. Therefore, it is subjected to both bending and torsional stresses. Hence the diameter of the shaft was determined using Equation (3) as in Khurmi and Gupta (2005) and Ogedengbe and Aderoba (2002).

$$
\left(d_{s}\right)^{3}=\frac{16}{\pi S_{s}} \sqrt{\left(\left(K_{b} M\right)^{2}+\left(K_{t} T\right)^{2}\right)}
$$

Where $d_{s}$ is the diameter of the stirrer shaft; $S_{S}$ is the allowable shear stress of the shaft material $\left(\mathrm{N} / \mathrm{m}^{2}\right)$; $K_{b}$ is the combined shock and fatigue factor applied to bending moment; $K_{t}$ is the combined shock and fatigue factor applied to torsional moment; $M$ is the bending moment $(\mathrm{Nm})$ and $T$ is the torsional moment $(\mathrm{Nm})$. Using Equation (5) alongside other existing equations given in Khurmi and Gupta (2005), Ogedengbe and Aderoba (2002) and Ogedengbe and Aderoba (2005), the diameter of the main stirrer shaft was determined to be $0.02 \mathrm{~m}$ and deep groove ball bearings designated as 61804 having bore of $0.02 \mathrm{~m}$ and outside diameter of $0.032 \mathrm{~m}$ was selected for its assembly.

Pre mixers design: The conceptual design utilizes two pre mixers of same size and configuration. Like the main mixer each of them consists of the pre mixing chamber, the stirrer impeller and the stirrer shaft. The pre mixing chambers were similar to the main mixing chamber (cylindrical) but smaller. Hence, the design parameters of the pre mixing chambers were calculated similar to that of the main mixing chamber using equation (1). After due consideration of the fact that $0.005 \mathrm{~m}^{3}$ by volume of each of the pre mixing chamber is able to serve for the $0.020 \mathrm{~m}^{3}$ of liquid soap to be produced in the $0.025 \mathrm{~m}^{3}$ by capacity of the main mixing chamber, in respect of the ingredient mix proportions, the radius and height of each of the pre mixing chambers were obtained to be $0.172 \mathrm{~m}$ and $0.215 \mathrm{~m}$ respectively. Also, four baffles, each having a width of $0.017 \mathrm{~m}$ are incorporated at $90^{\circ}$ to one another along the wall of the mixing chambers. In a manner similar to that of the main mixer, the design parameters of the other components of the pre mixers were determine using the same approach and equations. This resulted in impellers with a diameter of $0.086 \mathrm{~mm}$. Also, the diameter of the stirrer shaft of each of the pre mixers was calculated as $0.01 \mathrm{~m}$ while deep groove ball bearings designated as 61800 with bore of $0.01 \mathrm{~m}$ and outside diameter of $0.019 \mathrm{~m}$ was used with the stirrer shafts.

Drive system and power requirement: The machine is designed to transmit Power from an electric motor to the main stirrer shaft via a V-belt drive system and from the main stirrer to the pre mixers' stirrers via a geared drive system as earlier mentioned. Therefore, the determination of the pulleys, gears, belt and electric motor parameters is essential here. The diameter and speed of the driving and driven pulleys were estimated to give the stirring speed of $50 \mathrm{rpm}$ established from preliminary study and literature as appropriate for the mixing task in the main mixing chamber (Dickey and Fasano, 2004). These and the tensions in the belt and other parameters for belt selection were determined using the series of formulae available in Khurmi and Gupta (2005). Consequently, the Speed of the driving $\left(\mathrm{N}_{1}\right)$ and the driven $\left(\mathrm{N}_{2}\right)$ pulley was estimated as $40 \mathrm{rpm}$ and $50 \mathrm{rpm}$ respectively while the diameter of the driving $\left(D_{1}\right)$ and the driven $\left(D_{2}\right)$ pulleys were estimated as $60 \mathrm{~mm}$ and $48 \mathrm{~mm}$ respectively. This gives a main mixer stirrer speed of $50 \mathrm{rpm}$. The distance between the pulleys was estimated as $102 \mathrm{~mm}$. Hence, an A37 V-belt was selected for the open belt drive system utilized. Also, the driving and driven gears located on the main mixer stirrer and the pre mixer stirrer was estimated to have 75 teeth and 25 teeth respectively to give the pre mixer stirrer speed of $150 \mathrm{rpm}$ considered appropriate for the premixing task. Hence, the main mixer stirrer and the pre mixers stirrers' speed are respectively $50 \mathrm{rpm}$ and $150 \mathrm{rpm}$ which falls within the speed range appropriates for the mixers as reported by Dickey and Fasano (2004).

The power requirement of the belt drive system was determined according to Khurmi and Gupta (2005) as in Equation (4).

$$
P_{a}=\frac{2 \pi N_{2}\left(T_{1}-T_{2}\right) \frac{D_{2}}{2}}{60}
$$

Where $P_{a}$ is the power is transmitted through to the stirrer shaft; $N_{2}$ is the speed of the main stirrer pulley (driven pulley); $D_{2}$ is the diameter of the pulley fitted to the main stirrer; $T_{1}$ is the tension in the tight side of the belt; $T_{2}$ is the tension in the slack side of the belt. Also, the power $P_{b}$ required by the stirrer to overcome the viscous force by virtue of the fluid viscosity on the stirrer impeller was estimated according to Patil et al. (2015) using Equation (5).

$P_{b}=F \times \mu$

Where $\mathrm{F}$ is the shear force by the impeller and $\mu$ is the stirrer tangential speed. Consequently, by determining the $P_{a}$ and $P_{b}$ for all the mixers and adding them up the power requirement for the machine was obtained. Hence, a $1 \mathrm{Hp}(0.746 \mathrm{~kW})$ variable speed three phase electric motor was selected for the machine. The reduction gear electric motor sourced and used to 
power the machine has variable output speed from 40 $\mathrm{rpm}$ to $200 \mathrm{rpm}$ at a step of $20 \mathrm{rpm}$.

Frame design: The frame is a structure that supports the main mixing chamber, the pre mixing camber, the electric motor, the open belt drive system and the gear train arrangement. Hence, it must be strong enough to carry the weight of these components and as well withstand the vibration that may arise from operation of the machine. Also, the machine must be comfortable in operation for the human operator who is to use it

Design for average was adopted to estimate the design values of the frames' parameters as well as the location of the various component of the machine with respect to the frame. This is to ensure the comfort of the users. Hence, based on a set of anthropometric data collected during the field study the frame dimensions (i.e. $\mathrm{L} \times$ $\mathrm{B} \times \mathrm{H})$ is estimated as $0.49 \times 0.49 \times 0.64 \mathrm{~m}$ respectively while the pouring height for the pre mixers is $0.73 \mathrm{~m}$.

The frame structure was designed using $1 \frac{1}{2}$ inch angled bar. Two thicknesses of $3 \mathrm{~mm}$ and $5 \mathrm{~mm}$ of the angled bar that are commercially available were considered and employed for Finite element Simulation (FES) of the designed frame in INVENTOR 2018 software. The fixed type end connection was used in holding the frame members together as members were to be eventually welded together to give adequate rigidity. The frame was adequately loaded at appropriate locations according to the weights of the various components of the machine it is intended to carry at these locations before simulation.

Development and Performance Evaluation of the Machine: The machine was fabricated using metal cutting and metal joining processes. The metal cutting operation was done mostly with hack saw and cutting disc while the metal joining operation was done using electric arc welding technique and bolted joint for permanent and temporary joint respectively. The construction of the machine components, except for the bought-out ones, were done using mild steel material as it is readily available with good strength, ductility, weld ability, toughness and machinability properties. After construction, the developed machine was engaged to produce twenty (20) liters of liquid soap using the ingredients, water and the production procedural sequence earlier discussed. The machine developed was evaluated by training twenty-eight (28) prospective users randomly drawn from different communities, in Akure environs, on how to use the machine. Subsequently, the trained users were engaged to produce liquid soap using the machine. Thereafter they were made to give a feedback, in comparison with manual production task, on a questionnaire designed to assess the impact of the machine developed. Also, the quality of the liquid soap produced by the developed machine was compared with that of the liquid soap produced using manual stirring approach and the one produced using MM. The viscosity and turbidity value of the liquid soap samples were measured in the chemistry Laboratory of the Federal University of Technology Akure using viscometer and labtech turbidity meter respectively. These properties of the liquid soap were measured and considered as part of the machine evaluation metrics as they could give an indication of how well the ingredients were mixed with one another.

\section{RESULTS AND DISCUSSION}

The FES conducted on the machine frame revealed that the maximum displacement and the maximum induced normal stress reduces with increasing frame thickness (see Table 1). These are expected. However, the maximum deflection of the frame with the $3 \mathrm{~mm}$ and $5 \mathrm{~mm}$ angled bar is $0.06322 \mathrm{~mm}$ and $0.008147 \mathrm{~mm}$ respectively. Each of this deflection is apparently small in comparison to the size of the frame. Also, the design is quite safe as the maximum induced normal stress is way below the yield stress of the material even for the $3 \mathrm{~mm}$ thick frame. When the material properties is considered the FES results show that the Factor of safety of the frame with $3 \mathrm{~mm}$ and $5 \mathrm{~mm}$ thick angled bar is 19.3 and 92.8 respectively. This implies that the frame with the $3 \mathrm{~mm}$ angled bar, just like that of the 5 $\mathrm{mm}$ angled bar, is sufficient to support all loads carried by the framework. Hence, the $3 \mathrm{~mm}$ angled bar was adopted and used for the fabrication of the machine frame as it is cheaper. The $5 \mathrm{~mm}$ angled bar if used will lead to overdesign with an associated higher cost. The liquid soap production machine developed is shown in Fig. 2.

Table 1: FES Output

\begin{tabular}{llll}
\hline Machine frame thickness $(\mathrm{mm})$ & Max Displacement $(\mathrm{mm})$ & Max Normal Stress (MPa) & Factor of Safety \\
\hline 3 & 0.06322 & 10.72 & 19.3 \\
5 & 0.008147 & 2.231 & 92.5 \\
\hline
\end{tabular}

The machine is powered by an electric motor which drives the main mixing chamber stirrer using an open belt drive system. It engages a gearing arrangement to transmit the motor power and/or motion from the main 
stirrer shaft to the pre mixer stirrer shafts thereby driving the pre mixer stirrers of the pre mixing chambers. The fifteen (15) liters of water and Nitrosol with which the production process usually starts are added and/or charged directly into the main mixing chamber via its inlet valve. The rotary motion of the stirrers provides for adequate mixing of the ingredients. The other ingredients are to be premix hence they are charged into the pre mixing chambers which each has an outlet valve connected directly to the main mixing chamber through where the properly pre mixed ingredients are charged into the main mixing chamber wherein the main stirrer performs the ultimate mixing to ensure the homogeneity of the liquid soap produced. The finished product is collected via the machine outlet valve.



Fig. 2. The developed liquid soap production machine

The developed machine when tested was found to run smoothly over the period of operation. Summary of the results from the questionnaires administered to the prospective users who were engaged to use the developed machine to produce liquid soap and the supporting interviews revealed that the respondents were of the opinion that the machine is very good and reliable. The returned questionnaire, after analysis, revealed that all $(100 \%)$ of the respondents feel that the machine has helped to reduce operational fatigue greatly in comparison with the manual method of liquid soap production. The percentage of the respondents that agreed that the comfort experienced while using the machine is very high is 92.85 while only 7.14 reported an average rating in regard of the comfort experienced while using the machine. The liquid soap produced by the developed machine was found to have the quality provided in Table 2 in comparison with the manually produced and the MM produced ones.
Table 2. Comparison of the Viscosity and Turbidity of the liquid soap produced with the machine developed in this study and liquid

\begin{tabular}{llll}
\multicolumn{3}{c}{ soap produced through other means } \\
\hline S/N & $\begin{array}{l}\text { Liquid soap } \\
\text { samples }\end{array}$ & \multicolumn{2}{c}{ Quality metrics } \\
\hline & & $\begin{array}{l}\text { Viscosity } \\
\text { (mPa-s) }\end{array}$ & $\begin{array}{l}\text { Turbidity } \\
\text { (NTU) }\end{array}$ \\
\hline 1 & A & 20,090 & 497 \\
2 & B & 20,030 & 92 \\
3 & C & 20,090 & 43 \\
\hline
\end{tabular}

The liquid soap produce by the developed machine is represented as A, on Table 2, while the ones produced manually and by a $\mathrm{MM}$ is represented as $\mathrm{B}$ and $\mathrm{C}$ respectively. The exact value of the ingredients used in producing the liquid soap samples A and B are the same and these values are the same as the ones given earlier in this study. However, it is important to report herein that this study didn't have access to the exact values of the ingredients used in producing the liquid soap sample $\mathrm{C}$ as it is purchased in the market for the purpose of the evaluation. As can be observe on Table 2 , the viscosity of the liquid soap sample $A$ is at par with that of the liquid soap sample $\mathrm{C}$ while it is slightly higher than that of the liquid soap sample B. This could be explained from the fact that the liquid soap samples $\mathrm{A}$ and $\mathrm{C}$ possess stronger intermolecular bonds which account for their viscosity being higher than that of liquid soap sample B. The stronger intermolecular bonds could be ascribed to more efficient mixing action of the machine developed in this study which is satisfactorily at par with the commercially available MM.

Turbidity is an expression of the amount of light that is scattered by material dissolved in the liquid sample when a light is shined through the liquid sample. Hence, the turbidity of a liquid sample increases with the number of particles that dissolves in it. The turbidity of the liquid soap sample A, B and C were obtained as 497, 92 and 43 NTU respectively. This revealed that the turbidity of sample $\mathrm{C}$ is the lowest. This is not very surprising as the turbidity of a given liquid could be reduced considerably when excess water is added to such liquid. Many liquid soap manufacturers do practice this in other to increase the volume of liquid soap produce from a given quantity of liquid soap ingredients for optimum profit. Since this study does not have the detailed knowledge of the Ingredients-water composition of sample $\mathrm{C}$ it was suspected that excessive water has been added to the ingredients which should have reduced the turbidity thereby increasing the product output volume. However, for samples A and B whose ingredientswater compositions are known to be the same Table 2 revealed that the turbidity of sample $\mathrm{A}$ is higher. This could be interpreted to imply that the machine developed herein which was used to produce sample 
A liquid soap is able to stir the soap ingredients with water at a relatively higher and consistent speed in comparison to manual and/or hand mixing. Therefore, it can be inferred that when using the machine developed to produce liquid soap the ingredients and water mixture gel more quickly and easily to form a more homogeneous cloudy paste, when compared with hand mixing, which results in higher turbidity of sample A compared to sample B. The developed machine cost Seventy-Three thousand eight hundred naira only $(\mathrm{N} 73,800)$ (i.e. \$205) as estimated from the Bill of Engineering Measurement and Evaluation. This is considered economical in comparison with the commercially available MMs which cost as low as N1, 080,000 (i.e. $\$ 3,000$ ) and/or as high as $\mathrm{N} 25,200,000$ $(\$ 70,000)$. Also, since the component part can be sourced locally, it will facilitate maintenance which would be achieved usually at reduced cost compared to the MMs.

Conclusion: A prototype multistage mixing machine was designed, developed and evaluated for small scale and household liquid soap production. The machine runs smoothly in operation and reduces fatigue in the production process. The quality of liquid soap produced is better than that of the manually produced one. The machine is cheap to purchase and maintain as it was developed using locally available materials. Also, it is reliable and will facilitate and encourage local and domestic liquid soap production.

\section{REFERENCES}

Ajao, KR; Mustapha, K; Mahamood, MR; Iyanda, M (2010). Design and development of a pedal powered soap mixer. New York Science J. 3(1): 69

Ajao, KR; Ogunniyi, OJ; Ahmed, KL (2011). Development of equipment for making homemade laundry soap. J. Agric. Technol. 7(3): 567-574

Anon (2018). Prices of liquid soap making plants. Accessed 24 November, 2018. Available from: htttp://www.alibaba.com/

Bashir, H (2014). Soap manufacturing value chain, analysis, issues and solutions. Ind. Engineer. Let. 4(9): 1-2.

Charles, EO (2003). Virtual Chembook, ElmhurstCollege. Accessed 25 April, 2018. Available from: htttp://www.elmhurst.edu/ chm/vchembook/inde x.html.
Dickey, DS; Fasano, JB (2004). Mechanical design of mixing equipment. In: Paul, EL; Atiemo-Obeng, VA; Kresta, SM (ed) Handbook of Industrial Mixing: Science and Practice, John Wiley and Sons, Inc., 1247-1332.

Jirout, T; Rieger, F (2011). Impeller design for mixing of suspensions. Chem. Engineer. Res. Design. 89 (7): 1144-1151.

Khurmi, RS; Gupta, JK (2005). A textbook of machine design. 14th Edition, Eurasia Publishing House (PVT) LTD, Ram Nagar, New Delhi-110 055.

Kililiku, JC; Wambua, KS; Bitok, KF (2006). Design of a bar soap making machine for local soap industry. Department of Mechanical and Manufacturing Engineering, University of Nairobi. Project Number DMM.02/2006

Parvizi, S; Alamdari, EK; Hashemabadi, SH; Kavousi, M; Sattari, A (2016). Investigating factors affecting on the efficiency of dynamic mixers. Mineral Processing and Extractive Metallurgy Review. 37(5): 342-368.

Patil, DP; Shrotri, AP; Patil, VP; Mane, NS (2015). Design and development of a special purpose bidirectional mixer to maximize agitating performance. Inter. J. Mod. Stud. Mechanic. Engineer. 1(1): 1-7

Ogedengbe, TI; Aderoba, AA (2002). A computerized approach to design of mechanical power transmission shafts. Nig. J. Engineer. Res. Develop. 1(4): 36-46

Ogedengbe, TI; Aderoba, AA (2005). Computer aided selection of rolling contact bearing. Association for the Advancement of Modeling and Simulation Techniques in Enterprise (ASME). J. Model. B. 74(5): $1-18$

Warra AA (2013). A report on soap making in Nigeria using indigenous technology and raw materials. Afr. J. Pure. Appl. Chem. 7(4): 139-145. 